\section{AATS Awards Applications}

\section{Now Available at www.aats.org}

\section{August 2015 Deadline}

\section{AATS Critical Care Scholarship}

Provides an opportunity to expose cardiothoracic surgery residents to cardiovascular critical care by providing assistance to attend the Cardiovascular Thoracic (CVT) Critical Care Conference taking place October 1-3, 2015, at the Omni Shoreham Hotel in Washington, D.C.

- Eligible residents must be enrolled in either an ACGME accredited cardiothoracic surgical training program in the United States or RCPSC accredited cardiothoracic surgical resident program in Canada.

- Funded by the AATS Graham Foundation, the scholarship will provide a stipend of $\$ 500$ to the resident's institution to help offset the cost of travel and hotel accommodations. Additionally, the AATS Graham Foundation will provide complimentary registration to the course.

- Institutions will have the opportunity to select one resident to participate in this scholarship. Additional residents may be nominated by a Program Director, however they will be placed on a waiting list until the application process has concluded. If additional vacancies are available, the residents on the waiting list will be accepted on a first-come, first-served basis.

- The application deadline is August 15, 2015.

- Up to 30 recipients will be awarded on a first-come, first-served basis.

\section{Deadline: August 15, 2015}

To inquire for more information visit the AATS Web site or contact the AATS at admin@aats.org.

\section{Save the Dates for AATS Week 2016}

Aortic Symposium

May 12-13, 2016

New York, NY, USA

96th Annual Meeting

May 14-18, 2016

Baltimore, MD, USA

\section{Heart Valve Summit: Medical, Surgical, \& Interventional Decision Making}

October 1-3, 2015

Radisson Blu Aqua Hotel

Chicago, IL

\section{Course Directors}

David H. Adams, Mount Sinai Medical Center

Steven F. Bolling, University of Michigan

Robert O. Bonow, Northwestern University

Howard C. Herrmann, University of Pennsylvania

Nurse Planner

Michele Mistovich, RN, MS, Northwestern Memorial Hospital

\section{Course Overview}

Heart disease accounts for more fatalities than any other single or group causes of death in the United States. While national Guidelines inform the care, controversies in care within advancing technological and medical arenas demand collaborative methods of diagnosis and strategies for medical, surgical, and interventional management.

The Heart Valve Summit provides the perfect forum to address these challenges, bringing together cardiologists, surgeons, and other members of the cardiac care team through a variety of unique learning formats including challenging case studies, intense debates of controversial areas, and didactic lectures related to the forefront of our discipline.

\section{Course Highlights Include:}

- Basics of Aortic Stenosis

- Congenital Valve Disease

- Decision-Making: Less than Severe Regurgitation

- Degenerative Mitral Anatomy \& Physiology

- Guideline Controversies

- HOCM 2015

- My Most Interesting, Controversial, or Complicated TAVR Case

- Secondary Mitral Valve Regurgitation

- The Asymptomatic Patient

- The Cardiac Network Trials: Answers \& More Questions

\section{Target Audience}

The 2015 Heart Valve Summit is intended for cardiologists, interventional cardiologists, cardiothoracic surgeons, internists, nurses, physician assistants, and all health care professionals involved in the evaluation, diagnosis and/or management of VHD patients.

\section{Accreditation}

\section{Physicians}

This course has been approved for AMA PRA Category 1 Credits ${ }^{\mathrm{TM}}$.

\section{Nurses}

The American College of Cardiology Foundation is accredited as a provider of continuing nursing education by the American Nurses Credentialing Center's Commission on Accreditation. 